\title{
Large Gap Two-dimensional Topological Insulators with Significant Rashba Effect in Ethynyl and Methyl \\ Functionalized PbSn Monolayers
}

Yonghu Wang ${ }^{\mathrm{a}}$, Shuangying Lei ${ }^{\mathrm{a}, *}$, Neng Wan ${ }^{\mathrm{a}}$, Feng $\mathrm{Xu}^{\mathrm{a}}$, Hong $\mathrm{Yu}^{\mathrm{a}}$, Cuiyu $\mathrm{Li}^{\mathrm{b}}$, Jie Chen ${ }^{\mathrm{a}}$

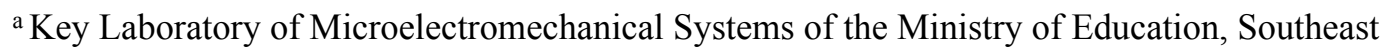
University, Nanjing 210096, China.

bAdvanced computing East China Sub-center, Suma Technology Co., Ltd., Kunshan, 215300, China.

*Corresponding author. E-mail address: lsy@seu.edu.cn (S. Lei)

(a)

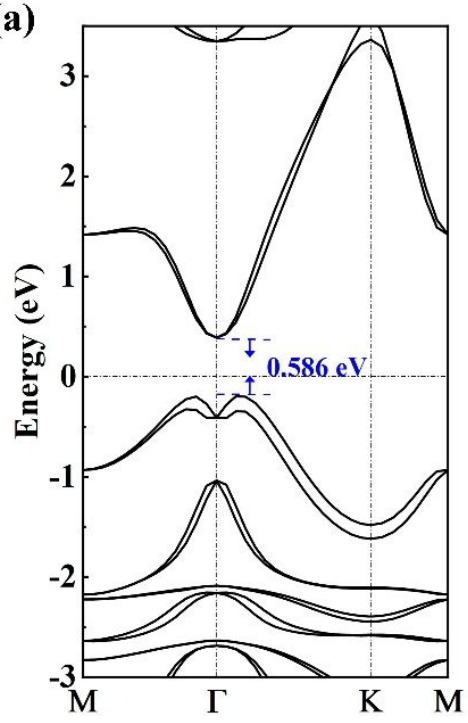

(b)

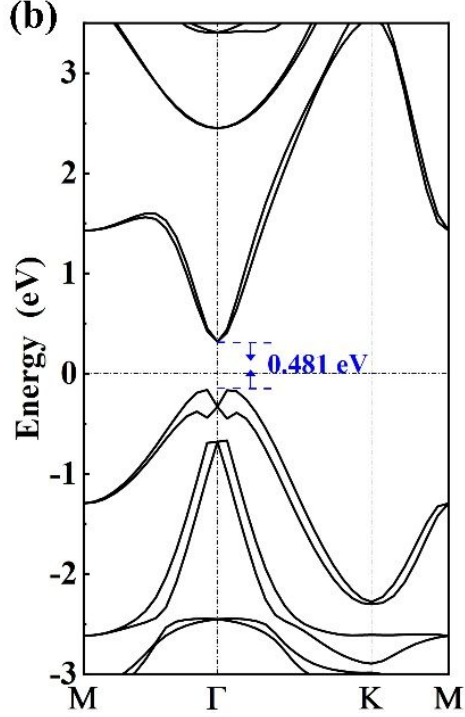

Fig. S1 HSE06 band structures of (a) $\mathrm{PbSn}\left(\mathrm{C}_{2} \mathrm{H}\right)_{2}$ with bandgap of $0.586 \mathrm{eV}$ and (b) $\mathrm{PbSn}\left(\mathrm{CH}_{3}\right)_{2}$ with bandgap of $0.481 \mathrm{eV}$. The Fermi level has been set to zero. 